\title{
Kostas Kampourakis and Tobias Uller (Eds.): Philosophy of Science for Biologists. Cambridge University Press: Cambridge, UK, 2020, $330+x$ pp., $£ 69.99$ (hardcover), ISBN: 9781108491839
}

\section{Guido I. Prieto ${ }^{1}$ (D)}

Published online: 15 June 2021

(C) The Author(s) 2021

It is a commonly held belief among philosophers of science that philosophy can contribute to scientific debates (and maybe even scientific progress) and that scientists would benefit both from reflecting philosophically on their subject matter and research practices, and from collaborating with philosophers. However, the relationship between science and its philosophy is a complex and constantly changing one, and it is quite often the case that the apparent gap between the two fields seems unsurmountable. One of the causes of this (though certainly not the only one) has to do with the way scientists and science teachers usually get schooled. In fact, philosophy of science normally does not play a central role in higher education in the sciences. In the cases in which philosophy laboriously percolates into science curricula, what finally reaches the class is often the presentation of a limited collection of stereotyped philosophical theories-typically those of Karl Popper and Thomas Kuhn-which sometimes even contribute to reaffirming the prejudices that science students may hold against philosophy.

Philosopher Kostas Kampourakis and evolutionary biologist Tobias Uller are not content with lamenting this state of affairs. They have been working for years in the intersection between science, philosophy and education, making a commendable effort to bridge those disciplines (see, e.g., Kampourakis 2013; 2014; Uller et al., 2020). Kampourakis' and Uller's recent edited volume Philosophy of Science for Biologists is one concrete example of their enterprise. The book aims at convincing practicing biologists that philosophical reflection is useful and beneficial for them and serves as a primer for those biologists who are willing to become acquainted with the philosophy of science. Additionally, the book is planned as a tool for teaching to biologists a philosophy of science curriculum that overcomes the one traditionally taught (for a discussion of the aims of the book, see Woodford 2021).

It should be kept in mind that Philosophy of Science for Biologists is neither a book on philosophy of biology nor a book on philosophy of science per se. Instead, as its title indicates, it is a book on the philosophy of science for biologists, for both students and teachers. But how would such a novel and much-needed book look like? What should the reader expect before opening it for the first time? A straightforward answer would be that the book

Guido I. Prieto

Guido.Prieto@rub.de

1 Department of Philosophy I, Ruhr University Bochum, 44801 Bochum, Germany 
should contain an up-to-date overview of the main topics in philosophy of science, written in an accessible way, and applied to concrete biological cases to make the topics appealing and significant for biologists. If the reader expects that, she will not be disappointed. This collection of essays features a healthy mixture of philosophers, historians, and biologists who have made a palpable effort to provide rich and updated presentations of a wide range of important topics (with a predictable slight bias towards evolutionary biology, given the editors' backgrounds) in an engaging and accessible fashion. Crucially, each topic is illustrated and exemplified with real biological cases or historical events, which impress with their breadth and amount. The volume features, for instance, discussions on concepts such as 'evolutionary novelty', the 'organism-as-machine' metaphor and 'social learning'; research like that on the causes of the end-Cretaceous mass extinction; historical events such as Lenski's experiments with Escherichia coli and the classical-balance controversy; and socially relevant issues such as eugenics and intersex.

The fifteen chapters of the book can be grouped into four thematic clusters. After an introduction where the editors set the tone of the book and anticipate the main topics to be covered in it, there are three chapters dealing mainly with scientific explanation and models. Angela Potochnik cautions biologists against the reductionist tendencies of explaining phenomena only in terms of single, overarching, mechanistic causes, by convincingly arguing that both causal dependencies and causal patterns are central to scientific explanation and that phenomena are usually the result of multiple interacting causal factors. The upshot of her examination is that multiple explanations accounting for the same phenomenon can coexist without conflict. However, Kevin McCain takes an almost opposite view in his essay. Mainly drawing on the theory of 'inference to the best explanation', he argues that, for a given set of observations, a single explanation can be found that is both better than its competitors and true. In their chapter, Emily C. Parke and Anya Plutynski turn their attention to the nature of models and model organisms. They underscore abstraction and idealization, which are strongly dependent on the scientist's research agenda and aims, as essential features of model building.

The next four chapters deal with concepts and conceptual analysis. Ingo Brigandt makes the interesting point that concepts are 'open-ended' and dynamic, rather than fixed products of past research findings. It is precisely by virtue of this dynamic character and 'forward-looking' nature, Brigandt explains, that they can guide scientific practice and provide intellectual identity to research programs and even entire disciplines. Another relevant feature of biological concepts that tends to get overlooked is that most of them are actually metaphors. This topic is scrutinized by Kostas Kampourakis, who persuasively argues that metaphors are useful tools for explaining, understanding, and communicating, but also warns biologists that an unreflective use of them may lead to overlooking relevant aspects of the studied phenomena that may be masked by the metaphors employed. In his contribution, David J. Depew traces key events in the history of evolutionary theory to illustrate the relevance of the conceptual aspects of science for scientific practice. For his part, Tim Lewens draws on examples taken from cultural evolution to show how conceptual analysis can help reduce conflict, solve disputes, and enhance communication within and among disciplines.

The three subsequent contributions focus on methods. Historian Erik L. Peterson detects a pattern of change in the methods employed by biologists through history and concludes from it that the methods in biology lie within a continuum between induction and deduction. In her chapter, Carol E. Cleland provides a lucid examination of the methods in the 'historical' sciences and finds key similarities and differences between these and the methods in the 'experimental' sciences. Afterward, she uses her insights to defend the scientific 
status of historical research in the life sciences and to confront and refute the pervasive view of a methodological hierarchy with experimental research on top and historical research at the bottom. Thomas Reydon contributes a chapter in which he discusses how philosophy can help clarify problems that arise in the classification of biological entities.

The last four chapters are quite heterogeneous and cover topics that are generally neglected in introductory books on the philosophy of science. Michael R. Dietrich, for instance, concentrates on scientific controversies examining the manifold ways in which they begin, persist, and end. Carrie Friese and Barbara Prainsack blur the dividing line between facts and values by showing how facts change values and how values inform the creation of scientific facts. Philosopher of biology Michael Ruse adds a chapter that substantially diverges from the rest of the volume in that it is essentially autobiographic. Finally, the editors close the book with a series of recommendations for teaching philosophy of science to biologists and a guide on how to use the book as an aid in that task.

Its broad range of topics is impressive. However, the volume omits comprehensive treatments of some important themes. In my opinion (for an alternative view, see Veigl 2021), the most prominent omission is ontological discussions in biophilosophy (but see Reydon's contribution) and a series of related and currently debated topics in (philosophy of) biology such as the nature of organisms and biological individuals, teleology and agency. General overviews of philosophy of science topics like causality, laws, and mechanisms, which are only briefly touched in some contributions, may also have been welcomed by the novice. Furthermore, some of the chapters in the book would have benefited from the inclusion of examples and case studies from present-day hot topics like microbiome research, climate change, or even the concept of race in biology.

Returning to the actual contents of the book, I would like to call attention to certain issues in the book that seem to run in the opposite direction to that which the editors set for it, that is, to offer a nuanced, critical, and updated picture of philosophy of science. One of them is McCain's proposal that, given some data and background evidence, it is possible to find a single best explanation and that this explanation "is the one that is true" (p. 42). Obviously, this position is highly problematic and some of the counter-arguments can indeed be found in Potochnik's contribution. A second issue is Peterson's somewhat simplistic characterization of the methods in the biological sciences as located within a spectrum between induction and deduction. Peterson contestably associates inductive science with Darwin's work (see, e.g., Marone \& Lopez de Casenave 2009) and with "many of the most significant discoveries in the history of the life sciences" (p. 189). He then contrasts it with the regrettable trend in contemporary biology towards getting fast publishable results to the detriment of theoretical breakthroughs, and suggests that inductive science could be an antidote against this tendency. But is it not in those current methods closest to induction (i.e., 'hypotheses-free' and 'high-throughput' correlation studies) where Peterson would find the foe he seems to be fighting? And, more generally, is it really inductive procedures from which groundbreaking ideas like natural selection emerge? These questions are particularly pertinent in an age of 'big data' science and should be critically and carefully addressed when teaching philosophy of science to biologists.

The last issue that deserves to be mentioned is Michael Ruse's self-proclaimed paternity over the philosophy of biology and his renewed attack on early-twentieth-century philosophers of biology, particularly Joseph H. Woodger. Without wanting to downplay Ruse's tremendous contributions to the philosophy of the life sciences, I cannot help pointing out that his depiction of early-twentieth-century philosophy of biology as "little literature [...] that is almost uniformly bad" and that "left much to be desired" (p. 277) has been recently put into serious question by the in-depth historiographical work of Nicholson and Gawne 
(2014; 2015; see also Peterson 2016). Moreover, some central research topics in presentday philosophy of biology pay a considerable debt to and stand in continuity with the earlytwentieth-century philosophy of biology that Ruse belittles (see Nicholson 2014; Baedke 2019).

Besides these points, Philosophy of Science for Biologists delivers on its promise of presenting a highly readable, up-to-date overview of contemporary philosophy of science for biologists. Moreover, some of its chapters offer good contextualized case studies that could also be used for teaching philosophy of biology to philosophers. I anticipate that the many questions the book motivates will give rise to lively discussions in the classroom and trigger philosophical reflections in the minds of its readers. I also hope the book will help biologists realize that philosophy of science is relevant for them, and makes their science all the more interesting.

Acknowledgements I thank Azita Chellappoo and Alejandro Fábregas-Tejeda for their helpful comments on the draft. All the opinions expressed in this review and any potential fault are entirely mine. I also acknowledge the financial support provided by the German Research Foundation (DFG; Project No. BA $5808 / 2-1)$.

Funding Open Access funding enabled and organized by Projekt DEAL.

Open Access This article is licensed under a Creative Commons Attribution 4.0 International License, which permits use, sharing, adaptation, distribution and reproduction in any medium or format, as long as you give appropriate credit to the original author(s) and the source, provide a link to the Creative Commons licence, and indicate if changes were made. The images or other third party material in this article are included in the article's Creative Commons licence, unless indicated otherwise in a credit line to the material. If material is not included in the article's Creative Commons licence and your intended use is not permitted by statutory regulation or exceeds the permitted use, you will need to obtain permission directly from the copyright holder. To view a copy of this licence, visit http://creativecommons.org/licenses/by/4.0/.

\section{References}

Baedke, J. (2019). O organism, where art thou? Old and new challenges for organism-centered biology. Journal of the History of Biology, 52, 293-324.

Kampourakis, K. (Ed.). (2013). The philosophy of biology: A companion for educators. Dordrecht: Springer. Kampourakis, K. (Ed.). (2014). Understanding evolution. Cambridge, UK: Cambridge University Press.

Marone, L., \& Lopez de Casenave, J. (2009). Nandúes, calandrias y la "creación” de la evolución. Hornero, $24(2), 65-72$.

Nicholson, D. J. (2014). The return of the organism as a fundamental explanatory concept in biology. Philosophy Compass, 9(5), 347-359.

Nicholson, D. J., \& Gawne, R. (2014). Rethinking Woodger's legacy in the philosophy of biology. Journal of the History of Biology, 47, 243-292.

Nicholson, D. J., \& Gawne, R. (2015). Neither logical empiricism nor vitalism, but organicism: what the philosophy of biology was. History and Philosophy of the Life Sciences, 37(4), 345-381.

Peterson, E. L. (2016). The life organic: The Theoretical Biology Club and the roots of epigenetics. Pittsburgh, PA: University of Pittsburgh Press.

Uller, T., Feiner, N., Radersma, R., Jackson, I. S. C., \& Rago, A. (2020). Developmental plasticity and evolutionary explanations. Evolution \& Development, 22(1-2), 47-55.

Veigl, S. J. (2021). Teaching biologists the philosophy of their time. Acta Biotheoretica. https://doi.org/10. 1007/s10441-020-09404-w

Woodford, P. (2021). A fish-hook for biologists: will they take the bait? Metascience. https://doi.org/10. 1007/s11016-021-00638-Z

Publisher's Note Springer Nature remains neutral with regard to jurisdictional claims in published maps and institutional affiliations. 